Acta chir belg, 1998, 98, 76-84

\title{
Abdominal Aortic Aneurysms in Octogenarians
}

\author{
H. Van Damme, N. Sakalihasan, C. Vazquez, Q. Desiron and R. Limet \\ Department of Cardiovascular, CHU Liège, Belgium
}

Key words. : Aortic aneurysm ; aorta, abdominal ; aged 80 and over ; ruptured aneurysm

\begin{abstract}
The decision on whether to operate or not abdominal aortic aneurysms (AAA) in elderly depends on the relative risk of the operation versus the natural course of the unoperated AAA.

From January 1984 to December 996, 138 patients, aged 80 years and older, were referred to our department for an aneurysm of $40 \mathrm{~mm}$ or more (transverse diameter) of the infrarenal abdominal aorta (95 asymptomatic, 15 painful, and 28 ruptured AAA). For 58 patients with asymptomatic AAA, operation was denied at referral because of transverse diameter less than $50 \mathrm{~mm}(\mathrm{n}=21)$, patient refusal $(\mathrm{n}=10)$ or unacceptable operative risk or poor general condition $(\mathrm{n}=27)$. Thirty-four of these observed AAA were ultimately operated after a mean delay of 41 months because of aneurysm enlargement $(n=15)$, aneurysm tenderness $(n=6)$ or rupture $(n=13)$. Overall, 52 patients had immediate $(n=37)$ or delayed $(n=15)$ elective repair of their AAA, with an in-hospital mortality of $5.7 \%$. Urgent operation was done for 21 patients with a painful AAA. Six patients died at hospital (28\% mortality rate). Emergent surgery was applied to 41 patients with ruptured AAA (including 13 AAA who ruptured during surveillance). The operative mortality in this subgroup attained $68 \%$.

Follow-up for the 77 survivors and the 24 non-operated patients averaged 43 months. The 5 -year survival (operative mortality included) is $47 \%$ for electively operated patients, $30 \%$ for urgently and $20 \%$ for emergently operated patients. For comparison, the 5-year survival of an age and sex matched Belgian population is $63 \%$. For the 24 medically followed AAA, the 5-year survival was $33 \%$. In six cases, the cause of death was rupture of the AAA. Of the 58 patients for whom operation was initially not considered, 19 (33\%) presented AAA rupture (13 operated in emergency and 6 who never came to surgery).

The operative outcome of AAA repair in octogenarians is less favourable than in the younger age group (3.6\% mortality after elective repair, $44 \%$ after operation for AAA rupture, according to our institution data).

The authors conclude that AAA surgery should not be denied to octogenarians on the basis of advanced age alone. They recommend a straightforward surgery for otherwise healthy octogenarians with AAA of 50 mm diameter, surveillance up to $60 \mathrm{~mm}$ for high-risk patients and no surgery for unfit, bedridden or demented patients.
\end{abstract}

\section{Introduction}

Abdominal aortic aneurysm is a disease primarily affecting elderly men. From population-based screening studies, one can estimate the prevalence of AAA (40 $\mathrm{mm}$ or more in transverse diameter) as $4 \%$ for octogenarians, with a male/female ratio of 5 over $1[1,2]$. At 80 years, life expectancy attains 7.52 years [3]. Currently, $3.5 \%$ of the Belgians are 80 years or older, what means that about 14.000 Belgian octogenarians could be expected to have an AAA of $40 \mathrm{~mm}$ or more. Ageing of the population is a health concerning problem. It is expected that the cohort of octogenarians will double in the coming 30 years. In the official Belgian mortality statistics of 1991 , aortic aneurysm is recorded as main cause in $0.55 \%$ of all deaths among octogenarians, and ranks fifteenth among all causes of death [3]. Bengtsson [4] found an analogous incidence of ruptured AAA in the Malmö autopsy study.
The medical decision making of surveillance or surgical repair should balance the relative operative risk against the natural course of the unoperated AAA. In other terms, it is essential to determine if both the risk of rupture and the safety of surgery justify operation.

The natural history of AAA is one toward rupture [5]. Aneurysms greater than $50 \mathrm{~mm}$ (transverse diameter) should be considered as a life-threatening but curable condition [6]. The annual rupture rate for a $50 \mathrm{~mm}$ AAA is estimated at $4 \%[5,7,8]$. Risk factors other than the aneurysm size, such as concurrent chronic obstructive lung disease, uncontrolled diastolic hypertension [7] and positive family history [9], increase the probability of aneurysm rupture.

Widespread agreement exists that AAA of $50 \mathrm{~mm}$ or greater should be repaired, except in individuals with major coexisting disease, resulting in excessive operative risk and reduced life expectancy [6]. Octogenarians often suffer concurrent systemic disease that adversely 
influence the operative risk. They are especially vulnerable from a pulmonary standpoint. A prophylactic operation with a mortality risk exceeding $7 \%$ is not easily suggested to an octogenarian for an asymptomatic AAA. On the other hand, the cumultive risk of death from AAA rupture attains $30 \%$ for a 80 -year old patient with a life expectancy of 7.52 years. Large AAA evolve, soon or late, to rupture that is always fatal if untreated. Most patients with ruptured AAA die before reaching the hospital, and for those who benefit surgery, operative mortality is as high as $70 \%$ [10].

Once an AAA is documented, aortic replacement before rupture should be invariably considered. This recommendation is based on the premise that aortic replacement will avoid death by rupture and extend useful life expectancy.

One should analyse which octogenarian could derive a clear advantage from surgery. Is the patient able to withstand major surgery? To answer these questions and to define an appropriate strategy, we reviewed our experience with AAA in octogenarians during the last 12 years.

\section{Material and methods}

A retrospective study was done for all octogenarians referred to our department for infrarenal AAA of 40 $\mathrm{mm}$ or more in diameter, from January 1984 to December 1996. We used the computerized vascular registry of our department to obtain demographic data and to analyse basic information on the diameter and aspect of the AAA, on comorbid conditions, on relevant medical history, and on the adopted management of the AAA (surveillance versus repair).

Aneurysms clinically presented as asymptomatic, painful or ruptured. Hospital records were analysed in detail, with special attention to the risk evaluation and the decision making on whether to operate or not. The only operation applied was standard aortic replacement. No exclusion techniques with extra-anatomic bypass or endoluminal stent graft were used. The operative outcome is analysed in function of the type of surgery (elective, urgent or emergent). Patients were subdivided in risk categories in function of age and cardiac, pulmonary and renal functional reserve, in accordance to the risk evaluation scale of the Joint Council of the Society of Vascular Surgery and the North American Chapter of the International Society of Cardiovascular Surgery [6]. Low risk patients are younger than 85 years, have a preserved cardiac function, mild or no obstructive lung disease and serum creatinine less than $20 \mathrm{mg} / \mathrm{l}$. Intermediate risk patients are aged 85 to 90 years, or have decreased cardiac output (ejection fraction between 20 and $50 \%$ ) or suffer angina at minimal exertion, or have incapacitating lung disease (forced expiratory volume (FEV1) between 800 and $1200 \mathrm{ml} /$ s), or impaired renal function (serum creatinine between 20 and $30 \mathrm{mg} / \mathrm{l}$ ): High risk patients are 90 years or older, or suffer congestive heart failure, or have ejection fraction lower than $20 \%$, or have severe respiratory insufficiency (FEV1 less than $800 \mathrm{ml} / \mathrm{s}$ ), or need home oxygen, or have significant renal failure (serum creatinine $>30 \mathrm{mg} / \mathrm{l}$ or haemodialysis). The operative outcome is further analysed in function of the risk category.

For comparison, the results of AAA repair in the younger than 80 years age group are given.

Operative mortality is defined as in-hospital mortality (only patients discharged from hospital are considered as operative survivors), rather than 30-day mortality.

An estimate of cost for elective and emergent surgery was made [11] A detailed analysis of the hospital charges was done for the most recent 40 patients operated electively $(n=20)(1993-1996)$ or emergently $(n=20)$ (1990-1996). Cost analysis concerns hospitalization, including stay in intensive care, pharmaceutics, transfusion products and medical fees. Cost effectiveness is calculated by dividing the overall cost of each group by the number of survivors. By this way, the bias of early deaths in the emergent group, falsely lowering the cost, is avoided.

Follow-up data were collected from the out-patient clinic (control visit last 6 months) in only $10 \%$ of cases, from a questionnaire send to the family physician in $75 \%$ ] and from telephone contact with relatives in $15 \%$. An estimate of quality of life after discharge from the hospital (mean delay 6 months) was made by ascertaining the degree of independence and mobility, using a score relating the ability to perform daily activities.

\section{Statistics}

Relationships between demographic data, clinical risk category, or aneurysm characteristics, and operative outcome were analysed univariately with Pearson's chisquare test or Fisher's exact test when appropriate.

Cumulative survival curves are constructed according the Kaplan-Meier life table method [12].

Survival data for the age and sex matched Belgian population were obtained from the life tables published in 1991 by the National Institute of Epidemiology [3].

\section{Results}

From January 1984 to December 1996, 138 octogenarians (21 females, 117 males) were referred to our Department for AAA. This represents $8.9 \%$ of all ( $n$ $=1552$ ) AAA referred during the same period. Their mean age was 82.9 years (range 80 to 94 ). Major patient characteristics are summarized in Table $\mathrm{I}$. 
Table I

Patient characteristics

\begin{tabular}{|l|l|}
\hline Number & $138(21 \mathrm{~F}, 117 \mathrm{M})$ \\
Mean age & 82.9 y (80-94) \\
Active smoking & $35 \%$ \\
Hypertension & $61 \%$ \\
Creatinine $>20 \mathrm{mg} / \mathrm{l}$ & $26 \%$ \\
COPD & $42 \%$ \\
FEVI $<1000 \mathrm{ml} / \mathrm{s}$ & $14 \%$ \\
Previous myocardial infarction & $45 \%$ \\
Congestive heart failure & $11 \%$ \\
Previous myocardial revascularization & $8 \%$ \\
Previous stroke & $6 \%$ \\
\hline
\end{tabular}

At referral, 95 patients presented an asymptomatic AAA (mean diameter $64 \pm 8 \mathrm{~mm}$ ) (Group A), 15 were admitted with a painful AAA suggestive for impending rupture (mean diameter $70 \pm 15 \mathrm{~mm}$ ) (Group B), and 28 with a ruptured AAA (mean diameter $78 \pm 16 \mathrm{~mm}$ ) (Group C).

In 10 of the group $\mathrm{C}$ patients, the AAA was first recognized at the moment of rupture, while in 18 patients it concerned rupture of a documented, medically followed AAA. Of the 95 patients initially seen outside urgent situation (group A), only 37 benefited elective repair within 2 months of referral. For the 58 other octogenarians with an asymptomatic AAA (mean diameter $60 \pm 20 \mathrm{~mm}$ ), operation was initially not considered for one of the following reasons: small aneurysm size (diameter less than $50 \mathrm{~mm})(\mathrm{n}=21)$, patient refusal $(n=10)$, unacceptable surgical risk or poor general condition $(n=27)$. For these patients, aneurysm size was monitored by serial ultrasonography or CT-scan every 6 to 12 months. Of the 58 observed patients, 34 ultimately came to surgery, after a mean delay of 39 months, because of aneurysm expansion to $50 \mathrm{~mm}$ or greater $(\mathrm{n}=11)$ or a growth rate of $0,5 \mathrm{~cm}$ or more in 6 months $(\mathrm{n}=4)$, aneurysm tenderness $(n=6)$ or aneurysm rupture $(n=13)$. This leaves 24 octogenarians who did not benefit aortic replacement during the study period (mean diameter $65 \mathrm{~mm}$ ). This group includes 6 patients with small $(<50 \mathrm{~mm})$ AAA, 5 patients who refused surgery and 13 patients deemed unfit for operation ( 2 patients suffered terminal malignancy, 2 patients had severe residuum from stroke, 2 were demented and 7 suffered incapacitating multisystem failure).

Overall 52 patients had early $(n=37)$ or delayed $(n=15)$ elective repair of their AAA. Their mean age was 81.5 years (range 80-86) and the mean transverse diameter of the AAA was $65 \pm 19 \mathrm{~mm}$. They all had a preoperative risk evaluation and respiratory preparation. Urgent operation was done for 21 patients with a painful AAA, including the 15 group $B$ patients and the 6 group A patients who developed aneurysm tenderness during surveillance. Their mean age was 83.3 years (range 80-94) and the mean diameter $69 \pm 20$ $\mathrm{mm}$. Emergent repair was done for 41 ruptured AAA, including 13 group A patients who ruptured a clinically followed AAA for which operation by first intention was declined. Thirty one patients had a known AAA, while in the ten other patients the AAA was not diagnosed before rupture. The mean diameter at the moment of rupture was $80 \pm 13 \mathrm{~mm}$ and the mean age 83.5 years (range $80-90$ ). There were 25 retained retroperitoneal ruptures and 16 free intraperitoneal ruptures. Severe hypotension $(70 \mathrm{mmHg}$ or less systolic blood pressure) occurred in 23 patients before aortic cross clamping, with in 12 cases episodes of unrecordable blood pressure, with a fatal cardiac arrest in 8 . Two other patients who developed cardiac arrest intraoperatively could be successfully resuscitated. One of them survived to operation for 38 months. The other died on day 12 .

A standard midline incision was used in 106 patients. In recent years, 8 patients had a retroperitoneal approach of their AAA by a left flank incision. A straight aortic tube was implanted in 16 patients, an aorto-biiliac bifurcation graft in 26 , an aorto-ilio-femoral graft in 18 and an aorto-bifemoral graft in 46 . Eight patients with ruptured AAA died before implantation of a graft. There was no significant difference in the operative technique (graft extension) between elective, urgent or emergent repair.

The operative outcome after elective, urgent or emergent repair is summarized in Table II. The median length of hospital stay was 15 (range 6 to 20), 32 (range 2 to 60 ), and 19 (range 1 to 52) days for elective, urgent or emergent repair respectively. The in-hospital mortality after elective repair was $5.7 \%(3 / 52)$. Three patients died, 2 from multiorgan failure on day 18 and 20,1 from myocardial infarction on day 4 . Three patients suffered perioperative myocardial infarction (1 fatal), 9 had postoperative respiratory failure (pulmonary infection in 7, adult respiratory distress syndrome (ARDS) in 2), 3 patients developed transient impairment of renal function (serum creatinine increase with $20 \%$ or more of the preoperative value), 1 evolved to haemodialysis (he finally died in multiorgan failure), and 1 patient suffered colon infarction, necessitating hemicolectomy (he finally died in sepsis and multiorgan failure).

For urgent repair, the in-hospital mortality was $28 \%$. Six patients died after a mean of 19 days (range 1 to 60 ). The cause of death was cardiac in 2 , respiratory in 1 and multiorgan failure in 3. One patient suffered ischaemic colitis that was medically managed, 3 had perioperative myocardial infarction ( 1 intraoperatively), 9 had respiratory failure, necessitating tracheotomy in 2 . 
Table II

Operative outcome

\begin{tabular}{|c|c|c|c|}
\hline & $\begin{array}{l}\text { Elective repair } \\
\quad(n=52)\end{array}$ & $\begin{array}{l}\text { Urgent repair } \\
(n=21)\end{array}$ & $\begin{array}{l}\text { Emergent repair } \\
\quad(n=41)\end{array}$ \\
\hline $\begin{array}{l}\text { Myocardial infarction } \\
\text { Respiratory failure } \\
\text { (necessitating tracheotomy) } \\
\text { Renal insufficiency } \\
\text { necessitating haemodialysis) } \\
\text { Ischaemic colitis } \\
\text { (necessitating colectomy) }\end{array}$ & $\begin{array}{lr}3 & (6 \%) \\
9 & (17 \%) \\
& - \\
4 & (8 \%) \\
& - \\
1 & (2 \%) \\
1 & (2 \%) \\
\end{array}$ & $\begin{array}{ll}3 & (14 \%) \\
9 & (43 \%) \\
2 & (9.5 \%) \\
4 & (19 \%) \\
1 & (5 \%) \\
1 & (5 \%) \\
& -\end{array}$ & $\begin{aligned} & 7(17 \%) \\
& 26(63 \%) \\
& 4(10 \%) \\
& 19(46 \%) \\
& 8(19.5 \%) \\
& 5(12 \%) \\
& 2(5 \%) \\
&\end{aligned}$ \\
\hline $\begin{array}{l}\text { Operative mortality } \\
\text { Cardiac } \\
\text { Multiorgan failure } \\
\text { Respiratory } \\
\text { Hypovolaemic shock }\end{array}$ & $\begin{array}{c}3(5.7 \%) \\
1 \\
2 \\
- \\
-\end{array}$ & $\begin{array}{c}6(28 \%) \\
2 \\
3 \\
1 \\
-\end{array}$ & $\begin{array}{c}28(68 \%) \\
5 \\
10 \\
4 \\
9\end{array}$ \\
\hline 5-year survival & $47 \%$ & $30 \%$ & $20 \%$ \\
\hline
\end{tabular}

Table III

Cost-effectiveness (charges for elective $(n=20)$ and emergent repair $(n=20)$

(1990-1996) divided by number of survivors)

\begin{tabular}{|l|c|c|c|}
\hline & $\begin{array}{c}\text { Ruptured } A A A(R 1) \\
(n=20) \\
(7 \text { survived })\end{array}$ & $\begin{array}{c}\text { Elective AAA repair (R2) } \\
(n=20) \\
(19 \text { survived })\end{array}$ & Ratio RI/R2 \\
\hline Hospitalization & $474,854^{*}$ & $138,990^{*}$ & 3.4 \\
Pharmaceutics & 197,699 & 36,871 & 5.4 \\
Transfusion products & 70,879 & 7,104 & 10.0 \\
Medical fees & 480,598 & 163,456 & 2.9 \\
\hline Overall & $\mathbf{1 , 2 2 6 , 4 0 4}$ & $\mathbf{3 4 8 , 2 3 6}$ & 3.5 \\
\hline
\end{tabular}

* (costs are in Belgian francs).

For emergent repair of ruptured AAA, the mortality rate was $68 \%(28 / 41)$. There were 10 intraoperative deaths. It concerned 2 fatal myocardial infarctions after graft implantation and 8 cardiac arrests on uncontrollable hypovolaemic shock before aortic cross clamping. Multiorgan failure was the main cause $(10 / 18)$ of the 18 postoperative deaths (1 to 19 days postoperatively). Twenty-six patients presented postoperative respiratory failure (bronchopneumonia in 18 , shock lung in 8 ). Twenty required mechanical ventilation beyond 3 days and 4 had tracheotomy. Five patients suffered ischaemic colitis necessitating hemicolectomy in 2 of them. Preoperative hypotension $(<70 \mathrm{mmHg}, \mathrm{n}=23$ ) was significantly correlated to operative mortality (18 died at hospital, $\mathrm{p}<0.01$ ). The mortality of emergent repair was further analysed for patients who ruptured a previously known AAA ( $=31)$. In 25 of them, coexistent medical problems provided an argument for medical surveillance. The mortality in that subgroup attained $80 \%$. In other words, $5(20 \%)$ of these patients previously turned down for elective repair on medical grounds, survived emergent operation after AAA rupture.

Cost evaluation for elective and emergent AAA repair is represented in Table III. For the 20 electively operated patients, the hospital stay averaged 14 days (extremes 2 and 31 ) versus 30 days (extremes 1 and $65)$ for ruptured AAA. Mortality attained 5\% (1/20) for elective repair and $65 \%(13 / 20)$ for emergent repair. Half of the deaths occured within 48 hours. This high early mortality falsely lowers the cost of emergent repair. Therefore, an estimate of the price to save one ruptured AAA was made by calculating the cost effectiveness of the procedure. Overall, the price to save one ruptured AAA is 3.5 times that of elective repair. Most important differences are the duration of stay in the 
intensive care unit and the tremendous requirement for transfusion products (fresh frozen plasma and concentrated red blood cells) in case of ruptured AAA.

Some complications influenced the mortality rate. Twenty of the 44 patients who developed respiratory failure died $(p<0.01)$. Only 1 of the 3 patients with transmural colon ischaemia survived $(\mathrm{p}<0.05)$. Nine patients necessitated reoperation for continuous bleeding ( 3 splenic injuries, 3 anastomotic leaks, 3 diffuse bleeding). Four of these patients ultimately died $(\mathrm{p}<$ $0.01)$.

The results of aneurysm repair in octogenarians in the last 7 years of the study period (1990-1996) were compared with those of the earlier period (1984-1989) (Table IV). The most considerable improvement was obtained for elective surgery $(4.7 \%$ operative mortality versus $10 \%, \mathrm{p} .0 .05)$. The high operative mortality for ruptured AAA was unchanged (66\% and $70 \%)$. For comparison, the recent results of aneurysm repair in the younger age group (less than 80 years) are also listed in Table IV.

The operative mortality was further analysed in function of the graduated risk category (Table V). For low-risk, otherwise healthy octogenarians, elective surgery could be performed with no operative mortality, versus a $10 \%$ mortality for elective AAA repair in high risk patients $(\mathrm{p}<0.01$ ). Urgent and emergent repair was characterized by a considerable operative mortality ( $28 \%$ and $68 \%$ respectively), whatever patient's risk profile. Age, considered alone, was not significantly determinant for operative mortality.
As already stated, for 58 patients of group A, a strategy of "watchful waiting" was adopted at initial assessment. In this group, 27 patients were considered to be at excessive risk for operation, and for them a deliberate decision had been made to pursue nonoperative management. Of these 58 observed AAA, 13 were ultimately operated in emergency for rupture, with 8 operative deaths ( 6 of the deaths belonged to the group of high-risk patients). Another 6 fatal ruptures (mean initial diameter $68 \pm 21 \mathrm{~mm}$, mean follow-up of 39 months) occurred in the group of 24 never operated patients. Three of them belonged to the group of high-risk patients, for whom elective repair was denied, and 3 were intermediate risk patients who refused $(n=2)$ or waited for $(n=1)$ elective operation. Overall, 9 of the 27 observed high-risk patients (believed unsuitable for operation when first seen) ultimately died from AAA rupture during surveillance.

Late follow-up for the 77 survivors and the 24 nonoperated patients averaged 43 months. Three patients were lost to follow-up at 6,9 and 15 months. For the 52 electively operated patients, the 3- and 5-year survival (operative mortality included) is $71 \%$ and $47 \%$ respectively. Their survival curve is depicted in Figure 1 with, for comparison, the estimated survival of the age and sex matched Belgian population (3-year and 5 -year survival of $78 \%$ and $63 \%$ respectively). For the 21 urgently and the 41 emergently operated patients, the 5-year survival (operative mortality included) is $30 \%$ and $20 \%$ respectively. An initial dramatic decline in the survival curve of these groups is due to an elevated

Table IV

Operative mortality rate

\begin{tabular}{|l|c|c|c|}
\hline & $\begin{array}{c}\text { Mortality } \geq 80 \text { years } \\
1984-1989 \\
(n=36)\end{array}$ & $\begin{array}{c}\text { Mortality } \geq 80 \text { years } \\
1990-1996 \\
(n=78)\end{array}$ & $\begin{array}{c}\text { Mortality }<80 \text { years } \\
1994-1996 \\
(n=380)\end{array}$ \\
\hline Elective repair & $10 \%(1 / 10)$ & $4.7 \%(2 / 42)$ & $3.6 \% \quad(12 / 334)$ \\
Urgent repair & $33 \% \quad(3 / 9)$ & $25.0 \%(3 / 12)$ & $5.8 \% \quad(1 / 17)$ \\
Ruptured AAA & $70 \% \quad(12 / 17)$ & $66.0 \% \quad(16 / 24)$ & $44.0 \% \quad(18 / 41)$ \\
\hline
\end{tabular}

Table V

Results versus risk profile

\begin{tabular}{|l|cl|cl|cc|c|}
\hline & \multicolumn{5}{|c|}{ Mortality } & \multirow{2}{*}{$\begin{array}{c}5 \text {-year } \\
\text { survival }\end{array}$} \\
\cline { 2 - 6 } & \multicolumn{2}{|c|}{ Elective repair } & \multicolumn{2}{|c|}{ Urgent } & \multicolumn{2}{|c|}{ Ruptured } & \\
\hline Low risk* $(\mathrm{n}=17)$ & $0 \%$ & $(0 / 10)$ & $33 \%$ & $(1 / 3)$ & $75 \%$ & $(3 / 4)$ & $66 \%$ \\
Moderate risk* $(\mathrm{n}=58)$ & $6.25 \%$ & $(2 / 32)$ & $18 \%$ & $(2 / 11)$ & $60 \%$ & $(9 / 15)$ & $25 \%$ \\
High risk* $(\mathrm{n}=39)$ & $10.00 \%$ & $(1 / 10)$ & $43 \%$ & $(3 / 7)$ & $73 \%$ & $(16 / 22)$ & $19 \%$ \\
Overall $(\mathrm{n}=144)$ & $5.70 \%$ & $(3 / 52)$ & $28 \%$ & $(6 / 21)$ & $68 \%$ & $(28 / 41)$ & \\
\hline
\end{tabular}

* For definition of "low risk" "moderate risk" and "high risk" categories, see MATERIAL AND METHODS in the text. 


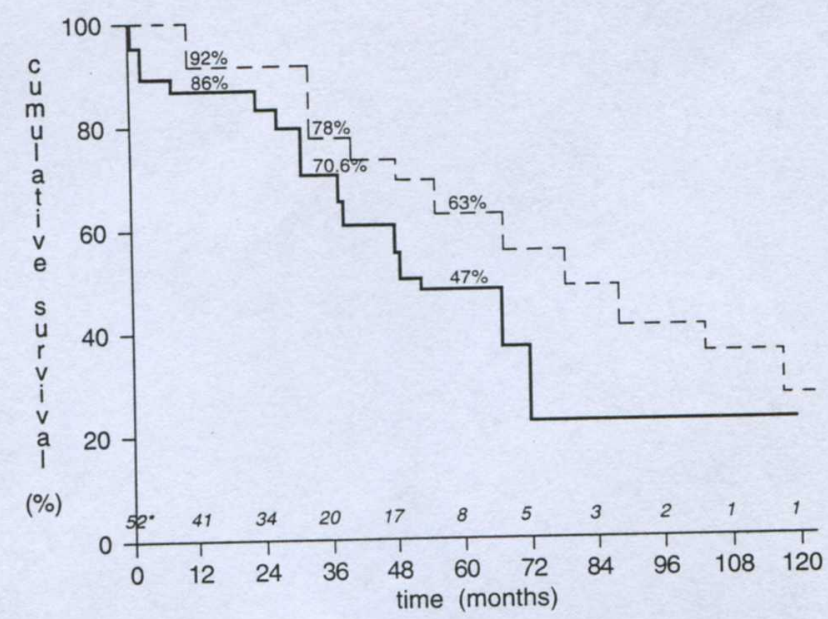

Fig. 1

* Number of patients at risk at a given time.

- Survival curve for 52 octogenarians electively operated for AAA.

-- Age and sex matched Belgian population $(>80 \mathrm{y})$.

in-hospital mortality. During follow-up, 53 patients died. Late mortality was cardiac related in $38 \%$, cancer in $19 \%$, respiratory or multiorgan failure in $11 \%$, stroke in $7 \%$, AAA rupture in $11 \%$ (6 patients of the 24 who did not undergo surgical correction of their AAA) and miscellaneous causes in $5 \%$. For 4 patients (9\%), we were unable to determine the cause of late death (Table VI).

Table VI

Causes of late death

\begin{tabular}{|l|r|c|}
\hline Cardiac & 20 & $(38 \%)$ \\
Cancer & 10 & $(19 \%)$ \\
Stroke & 4 & $(7.5 \%)$ \\
Respiratory & 6 & $(11 \%)$ \\
AAA surveillance and rupture & 6 & $(11 \%)$ \\
Miscelaneous & 3 & $(5.5 \%)$ \\
Unknown & 4 & $(7.5 \%)$ \\
\hline
\end{tabular}

Complete data for estimation of quality of life after discharge from the hospital were available for 59 of the 77 survivors. Ninety percent $(53 / 59)$ returned to a comparable or even better mental status and physical activity. The results were even better after elective surgery (quality of life assessed in 42 of the 49 survivors) : $93 \%$ (39/42) declared to enjoy an identical or even better life-style. After repair of ruptured AAA, convalescence was longer (13 survivors, quality of life assessed in 7) and $70 \%(5 / 7)$ regained a reasonable quality of life (able to care for themselves). Of the 77 survivors, 20 benefited convalescence in a nursing home (temporary for 11, definitely for 9). For the 24 nonoperated patients, 5-year survival was $33 \%$. During follow-up, 6 of them suffered fatal rupture of their AAA. Survival rates for low, intermediate and highrisk patients are $66 \%, 25 \%$ and $19 \%$ respectively at 5 years $(\mathrm{p} .0 .05)$.

\section{Discussion}

Repair of AAA in selected octogenarians can be done with a reasonably low morbidity and mortality. At our department, elective repair in octogenarians has a mortality rate that is 1.3 times higher than that for non-octogenarians $(4.7 \%$ versus $3.6 \%$ for the period 1990-1996). The same is true for urgent or emergent repair (Table IV). Most contemporary reports on elective AAA repair in patients aged 80 years or older mention an operative mortality that is approximately two times higher than in younger patients [13-18]. (Table VII). For emergent repair or ruptured AAA, the difference in results obtained in the two age groups is less evident. Outstandingly good results as obtained at the Cleveland Clinic [19] $(3.8 \%$ and $29 \%$ mortality for elective and emergent repair in octogenarians, versus $1.2 \%$ and $26 \%$ in the younger age group) are not at the reach of all centers. Elderly patients often present concomitant systemic disease (Table I). The risk profile allows to evaluate the relative operative risk (Table V). For "otherwise healthy" octogenarians with

Table VII

Published series

\begin{tabular}{|l|c|c|c|c|c|c|c|}
\hline Author (ref.) & Study period & $\mathrm{Nb}$ & $\begin{array}{c}\text { Elective repair } \\
\text { Mortality }\end{array}$ & $5-y$ survival & Nb & $\begin{array}{c}\text { Ruptured AAA } \\
\text { Mortality }\end{array}$ & 5 -y survival \\
\hline Treiman (16) & $1963-1981$ & 35 & $8.6 \%$ & $14 \%$ & 17 & $59 \%$ & $29 \%$ \\
Johnston (32) & 1986 & 51 & $10.0 \%$ & - & & & \\
Robson(17) & $1980-1988$ & 14 & $0 \%$ & - & 7 & $93 \%$ & $71 \%$ \\
Glock (14) & $1972-1987$ & 29 & $67 \%$ & $64 \%$ & 11 & $91 \%$ & $30 \%$ \\
Dean (13) & $1985-1992$ & 18 & $5.5 \%$ & $60 \%$ & 25 & $24 \%$ & $58 \%$ \\
Paty (18) & $1978-1991$ & 77 & $3.0 \%$ & $41 \%$ & 7 & $29 \%$ & \\
O'Hara (19) & $1989-1993$ & 53 & $3.8 \%$ & $47 \%$ & 41 & $68 \%$ & $20 \%$ \\
This series & $1984-1997$ & 52 & $5.7 \%$ & $14 \%$ & \\
\hline
\end{tabular}


no vital organ disease, elective AAA repair could be done with no mortality. For intermediate-risk and highrisk patients, mortality rates increase to $6.25 \%$ and $10 \%$. It is note worthy that in case of ruptured AAA, this difference in mortality between the different risk categories is no longer evident. This can be explained by the intrinsic fatality of ruptured AAA. Despite most recent progress in perioperative care, hypovolaemic shock is poorly tolerated by octogenarians, whatever their comorbid conditions. Critical hypotension involves multiorgan failure, a leading cause of postoperative death $[13,14,19,20]$.

We have put the limit of AAA size at $50 \mathrm{~mm}$ for elective repair in fit octogenarians. AAA rupture before the diameter reaches $50 \mathrm{~mm}$ is less frequent $[8,20]$. Two randomized trials are currently underway to compare operative management of small ( 40 to $55 \mathrm{~mm}$ ) AAA versus clinical observation $[22,23]$. The Joint Council of the Society for Vascular Surgery and the North American Chapter of the International Society of Cardiovascular Surgery published in 1992 recommended indications for operative repair of AAA [6]. The influence of advanced age and systemic vital organ disease (heart, lung, kidney) was evaluated. Compared to the optimal results obtained for elective repair in younger age groups (mortality rate less than $5 \%$ ), there is a 1 to $2 \%$ added mortality for low-risk patients (for risk criteria, see Material \& Methods). For moderate risk patients (about $30 \%$ of the octogenarians belong to that risk category), a 3 to $5 \%$ added mortality should be considered in the risk evaluation. For high-risk patients ( $15 \%$ of the elderly belong to that category), the operative risk increases with 7 to $10 \%$. Pulmonary complications and respiratory failure are leading causes of postoperative morbidity in elderly patients [17]. A 3-day course of preoperative pulmonary preparation with spirometry and bronchodilatators, as well as early extubation and postoperative nasotracheal suction, intensive chest physiotherapy and adequate pain-control with continuous epidural analgesia could obviate most of this respiratory morbidity and aid surgical recovery $[19,24-28]$. Preoperative coronary revascularization as well as haemodynamic optimization as guided by pulmonary artery catheter monitoring allow to minimize postoperative adverse cardiac events and renal functional impairment. In some frail elderly patients with severe comorbidity, the predicted operative mortality for aortic replacement approaches the estimated rate of AAA rupture. This constitutes the grey area of indecision for elderly patients at risk, who would not derive a clear advantage from surgery. The Joint Committee suggested a "wait and see" policy for high risk patients with AAA less than $60 \mathrm{~mm}$ in diameter. Once the aneurysm enlarged beyond the $60 \mathrm{~mm}$ limit, the risk of rupture becomes considerable. Repair of such huge AAA should be considered since the assumed benefit in terms of rupture prevention outweights the potential operative risk. As already stated, rigorous preoperative medical support and optimized perioperative care allow to achieve reasonable results for elective repair in these high-risk patients (mortality rates of 5 to $10 \%$ ) [24-28]. The only causes for whom nonoperative management is justified are unfit patients with a very poor outlook, a life expectancy of less than two years due to overwhelming medical problems, such as advanced metastatic malignancy or end-stage vital organ disease, and entirely dependent bedridden or demented patients with an unacceptable low quality of life $[6,14,19]$.

A "wait and see" policy entails some inherent risks. There is an unpredictable but likely exponential growth of the AAA over time $[8,21,29]$ while patient's general condition will deteriorate by the ageing process. Leaving a 50 to $60 \mathrm{~mm}$ AAA unoperated exposes the patient to a considerable aneurysm related mortality $[5,21]$. In our series, $24 \%(14 / 58)$ of the 58 medically followed AAA (mean diameter $60 \pm 20 \mathrm{~mm}, 37$ measuring 50 $\mathrm{mm}$ or more) ended up with fatal rupture over a mean observation period of 39 months. We recently published the outcome of 114 medically followed AAA [29]. Over a 26.8-month surveillance period, there were $19(17 \%)$ ruptures, of which 6 were fatal. Even for small AAA, the risk of rupture exists. In the series of Brown [21], the annual risk of rupture of a 50 to $60 \mathrm{~mm}$ AAA was $3.4 \%$ in the group of 155 medically followed patients, deemed at unacceptable surgical risk. Cronenwett [7] observed $6(9 \%)$ ruptures among 67 nonoperated patients followed over 36 months for small $(<55 \mathrm{~mm})$ AAA.

Octogenarians suffering AAA ask for special consideration. In our series, $20 \%$ of the AAA were ruptured at referral. Of these 28 patients, 18 had a documented AAA that was conservatively managed by their family doctor. This reflects the reluctance of general practitioners to refer their elderly patients with a documented asymptomatic AAA for elective repair. Primary care physicians often make an incorrect assessment of operative risk and grossly underestimate life expectancy of the elderly and the rupture rate of AAA. They erroneously assume that advanced age is a contraindication to surgery.

Controversy about management of ruptured AAA in elderly still exists [13]. A decade ago, an official recommendation in England (Confidential Enquiry into Perioperative Deaths - CEPOD [30]) suggested to withhold surgery for AAA rupture at 80 years or older. None of the octogenarians operated for rupture in the district hospitals survived. Also argued was the tremendous cost for the health insurance. At our institution, the cost to save one patient with ruptured AAA 
was evaluated at 1.2 million $\mathrm{BF}$, versus $350.000 \mathrm{BF}$ for successful elective AAA repair [11]. Dean [13] and Johansen [20] calculated analogous costs in both groups. In a more recent report from the Mayo Clinic, no single preoperative criterion could be identified justifying withholding care from patients with a ruptured AAA [24]. Forty-four percent of their octogenarians, operated on for rupture, survived.

An ethical problem and dilemma raises when an AAA ruptures in a patient who had already been turned down for elective repair on medical grounds or because of patient refusal [31]. In such an emergency situation, there is no time left for risk evaluation or open discussion with the patient or his family. The surgeon should take his full responsibility: no resuscitation at all or an aggressive approach. We are proponents of surgery for all ruptured AAA reaching the hospital alive, since it is the only reasonable chance of survival that can be offered to the patient $[10,24]$. In case of preoperative cardiac arrest, the chances of survival are reduced, but not inexistant. At the Mayo Clinic, $20 \%$ of these patients survived to operation [24]. An opposite point of view is given by Dean [13] and Johansen [20], who did not see any realistic hope for recovery of patients in profound haemodynamic shock due to AAA rupture. Consequently, they questioned the appropriateness of a heroic attempt of surgical repair. Emergent repair of ruptured AAA for which elective repair was previously denied, deemed not to be fruitless, since in our series, $20 \%(5 / 25)$ survived. In the series of Piotrowski [31], 17\% (3/18) of similar patients survived to operation for ruptured AAA. Only for patients in a preterminal condition prior to rupture, surgical abstinence in case of rupture can be considered $[6,13]$.

Long-term follow-up after elective AAA repair in elderly gives a 5-year survival of approximately $50 \%$, what is lower than that of an and sex matched general population (mean 5-year survival 63\%) [19]. This illustrates that patients with AAA commonly suffer concurrent cardiac disease and are exposed to a higher heart-related mortality $[2,19,32]$. Other authors report a survival rate after successful elective repair that parallels that of the general population [13$15,18]$. Most survivors retain a gratifying quality of life $[13,15,33,34]$.

Direct graft replacement of AAA is the standard of care. Some less invasive alternatives to conventional AAA resection have been proposed, in an attempt to reduce procedure related mortality and morbidity, especially for patients at prohibitive operative risk. Wrapping of the AAA [35] is actually abandoned as an obsolete technique. Aneurysm exclusion by ligation of the neck or the iliac arteries, associated with subsequent axillo-bifemoral bypass, was very popular a decade ago. But the results of non-resective treatment (7.7\% mortality rate [36] ) are not superior to those of standard repair [26]. Even more important is the fact that the induced thrombosis is not a guarantee against ulterior rupture of the unresected aneurysm [37]. In the series of Pevec \& Blaisdell [26 cases], 3 patients $(11.5 \%)$ suffered subsequent rupture [36]. Today, its anticipated safety and efficacy is questioned and the technique has been disfavoured [26, 27, 37]. Endovascular stent-grafting is an attractive, innovative concept, clinically introduced by Parodi [38]. However, not all AAA are eligible for "endografting" (too short neck, tortuous or calcified iliac arteries). There is also a technique-related morbidity (cholesterol embolization [39], contrast induced nephropathy, graft overlap of the renal artery orifices, local vascular complications, such as iliac or femoral artery trauma by the relatively inflexible $24 \mathrm{~F}$ access sheath) and device-related malfunction (attachment fracture, migration, perigraft leak). In a recent series, a $3.2 \%$ mortality was reported for elective procedures [40]. This minimal invasive technique is still under investigation, and its long-term efficacy in preventing rupture remains to be proven [4043].

We conclude that AAA repair can be performed safely in carefully selected octogenarians, even if the results are not so excellent as in the younger age group. Advanced age, in itself, should not be an exclusion criterion of AAA repair. Management of octogenarians with a non-ruptured AAA of $50 \mathrm{~mm}$ or more requires sound clinical judgement in each case, and fully information of the patient and his family. On the basis of our data, we recommend a straightforward surgery for "otherwise healthy" octogenarians with a $50 \mathrm{~mm}$ or more AAA, with a rapidly expanding AAA (growth rate exceeding $0.5 \mathrm{~cm} / 6$ months) or with a symptomatic AAA. For "at risk" patients, we adopt watchful waiting and AAA surveillance up to $60 \mathrm{~mm}$. For unfit individuals with life expectancy of less than 2 years and for mentally or physically severely disabled patients, no surgery should be performed.

\section{References}

Morris G., HubBard C., Quick C. An abdominal aortic aneurysm screening programme for all males over the age of 50 years. Eur J Vasc $1994 ; 8$ : 156-160.

Ping A., Van Der Does E., Van Urk H., HofMAN A., DE JONG P. Aneurysm of the abdominal aorta in older adults : the Rotterdam Study. Am J Epid 1995; 142 : 1291-1299.

3. Institut d'Hygiène et d'Epidémiologie - Ministère de la Santé Publique. Life expectancy and proportional mortality rates in Belgium. 1991.

4. Bengtsson H., Bergqvist D. Ruptured abdominal aortic aneurysm: a population-based study. J Vasc Surg 1993; 18: 74-80.

5. Szilagyi D., Elliott J. P., Smith R. F. Clinical fate of the 
patient with asymptomatic abdominal aortic aneurysm, and unfit for surgical treatment. Arch Surg $1972 ; 104$ : 600-606.

6. Hollier L., TAYLOR L., Ochsner J. Recommended indications for operative treatment of abdominal aortic aneurysm. J Vasc Surg $1992 ; 15$ : 1046-1056.

7. Cronenwett J. L., Murphy T. H., Zelenock G. B., et al. Actuarial analysis of variables associated with rupture of small abdominal aortic aneurysms. Surgery $1985 ; 98: 472-483$.

8. Nevitt M. P., Ballard D. J., Hallett J. Jr. Prognosis of abdominal aortic aneurysm. A population-based study. $N$ Engl $J$ Med 1989; a 2321 : 1009-1014.

9. Verloes A., Sakalihasan N., Koulischer L., Limet R. Aneurysms of the abdominal aorta. Familial and genetic aspects in three hundred thirteen pedigrees. $J$ Vasc Surg 1995 ; 21 : 646655.

10. Budd J., Finch D., Carter P. A study of the mortality from ruptured abdominal aortic aneurysm in a district community. Eur J Vasc Surg $1989 ; 3: 351-354$.

11. Goffard C. Etude comparative des coûts d'une chirurgie de l'anévrysme de l'aorte abdominale sous-rénale en condition élective et en situation de rupture. Thèse de doctorat, licence en Sciences Sanitaires, 1993, Université de Liège.

12. Collett D. Modelling survival data in medical research. London, Chapman and Hall, $1994: 28-51$.

13. Dean R., Woody J., Enarson C., Hansen K., Plonk G. Operative treatment of abdominal aortic aneurysm in octogenarians. When is too much too late? Ann Surg 1993; 217: 721728.

14. Glock Y., Smile E., Dalous P., et al. Abdominal aortic aneurysm in octogenarian patients. J Cardiovasc Surg 1990 ; 31 : 71-76.

15. O'Donnell T. F. Jr, Darling R. C., Linton R. R. Is 80 years too old for aneurysmectomy? Arch Surg 1976; 111 : 1250-1257.

16. Treiman R. L., Levine K. A., Cohen J. L., Cossman D. V., Foran F., LEVIN P. M. Aneurysmectomy in the octogenarian. A study of morbidity and quality of survival. Am J Surg 1982; 144 : 194-197.

17. Robson A. K., Currie I. C., Poskitt K. R., Scott D., Baird R. N., Hor rocks M. Abdominal aortic aneurysm repair in the over eighties. Br J Surg $1989 ; 76$ : 1018-1020.

18. Paty P., Lloyd W., Chang B., Darling R. III, Leather R., SнAн D. Aortic replacement for abdominal aortic aneurysm in elderly patients. Am J Surg 1993; 166 : 191-193.

19. O'Hara P., Hertzer N., Krajewski L., Tan M., Xiong X., BEVEN E. Ten-year experience with abdominal aortic aneurysm repair in octogenarians : early results and late outcome. $J$ Vasc Surg $1995 ; 21: 830-838$.

20. Johansen K., Kohler T. R., Nicholls S. C., Zierler R. E., Clowes A. W., Kazmers A. Ruptured abdominal aortic aneurysm : the Harborview experience. J Vasc Surg 1991; 13 : 240-247.

21. Brown P., Pattenden R., Vernooy C., Zelt D., Guteluis J. Selective management of abdominal aortic aneurysm in a prospective measurement program. J Vasc Surg $1996 ; 23: 213-$ 222.

22. Lederle F., Wilson S., Johnson G., et al. Design of the abdominal aortic aneurysm detection and management study. $J$ Vasc Surg $1994 ; 20$ : 296-303.

23. Powell J., Greenhalgh R., Ruckley C., Fowkes f. Prologue to a surgical trial. Lancet $1993 ; 342: 1473-1474$.

24. Gloviczki P., Pairolero P. C., Mucha P. et coll. Ruptured abdominal aortic aneurysms : repair should not be denied. $J$ Vasc Surg $1992 ; 15: 851-859$

25. Hallett J., Bower T., Cherry K., Glovicki P., Joyce J., PaIROLERo P. Selection and preparation of high risk patients for repair of abdominal aortic aneurysm. Mayo Clin Proc 1994; $69: 763-768$.
26. Hollier L., Reigel M., Kazmier F., Pairolero P., Cherry K., Hallett J. Conventional repair of abdominal aortic aneurysm in the high-risk patient : a plea for abandonment of nonresective treatment. $J$ Vasc Surg $1986 ; 3$ : 712-717.

27. Pairolero P. Repair of abdominal aortic aneurysm in the highrisk patients. Surg Clin N Am 1989; 69 : 755-763.

28. Robinson J., Beckett C., Mills J., Elliott B., Roettger R. Aortic reconstruction in high-risk pulmonary patients. Ann Surg $1989 ; 210: 112-117$

29. Limet R., Sakalihasan N., Albert A. Determination of the expansion rate and incidence of rupture of abdominal aortic aneurysms. J Vasc Surg $1991 ; 14$ : 540-548.

30. Buck N., Devlin H., Lunn J. The report of a Confidential Enquiry into Perioperative Deaths. London : Nuffield Provincial Hospital Trust, Kings Fund, 1987.

31. Piotrowski J., Akhrass R., Alexander J., Yuhas J., Brandt C. Rupture of known abdominal aortic aneurysm : an ethical dilemma. Am J Surg 1995; 61 : 556-559.

32. Johnston W., Canadian Society for Vascular Surgery Aneurysm Study Group. Non-ruptured abdominal aortic aneurysm : sixyear follow-up results from the multicenter prospective Canadian aneurysm study. J Vasc Surg $1994 ; 20$ : 163-170.

33. Currie I., Scott D., Robson A., Horrock M. Quality of life of octogenarians after aneurysm surgery. Ann R Coll Surg Engl $1992 ; 74$ : 269-273.

34. Magee T., Scott D., Dunkley A., et al. Quality of life following surgery for abdominal aortic aneurysm. Br J Surg $1992 ; 79: 1014-1016$.

35. Stallworth J., Ramirez A. A method of treatment for complicated aneurysm of the abdominal aorta. Ann Surg 1969; $169: 282-289$

36. Pevec W., Holcroft J., Blaisdell W. Ligation and extraanatomic arterial reconstruction for the treatment of aneurysms of the abdominal aorta. J Vasc Surg $1994 ; 20$; 629-636.

37. Marnette J. M., Creemers E., Trotteur G., Limet R. Results of an exclusion technique for treatment of abdominal aortic aneurysm. Cardiovasc Surg $1995 ; 3$ (1) : 26-29.

38. Parodi J., Palmaz J., Barone H. Transfemoral intraluminal graft implantation for AAA. Ann Vasc Surg 1991 ; 5 : 491-499.

39. Thompson M., Sмith J., NAYLor R., et al. Microembolization during endovascular and conventional aneurysm repair. $J$ Vasc Surg 1997 ; 25 : 179-186.

40. Balm R., Eikelboom B., May J., Bell P., Swedenborg J., Coluiv J. Early experience with transfemoral endovascular aneurysm management (TEAM) in the treatment of aortic aneurysms. Eur J Vasc Endovasc Surg 1996; 11 : 214-220.

41. White G., May J., McGraham T., et al. Historic control comparison of outcome for matched groups of patients undergoing endoluminal versus open repair of abdominal aortic aneurysms. J Vasc Surg 1996; $23: 201-212$.

42. MOORE W., RUtherford R. Transfemoral endovascular repair of abdominal aortic aneurysm : results of the North American EVT phase 1 trial. J Vasc Surg 1996 ; 23 : 543-553.

43. Yusuf S., Whitaker S., Chuter T., et al. Early results of endovascular aortic aneurysm surgery with aortouniiliac graft, controlateral iliac occlusion, and femorofemoral bypass. $J$ Vasc Surg $1997 ; 25$ : 165-172.

Submitted : 17 July 1997.

Accepted : 6 September 1997.

Dr H. Van Damme

Department of Cardiovascular Surgery

CHU Sart-Tilman (B 35)

B-000 Liège 